\section{Estudo \\ CoDebate}

em Testão

Planejamento
Revista Estudo \& Debate, Lajeado, v. 25, n. 2, 2018. ISSN 1983-036X

DOI: http://dx.doi.org/10.22410/issn.1983-036X.v25i2a2018.1683

\title{
VAREJO DE MODA EM CUIABÁ: ESTUDO DO MODELO DE NEGÓCIO DE EMPRESAS DO RAMO E A ADERÊNCIA ÀS EXPECTATIVAS DE MERCADO
}

\author{
Isadora Ananda dos Santos Astrissi ${ }^{1}$, Diogo Barbosa Leite ${ }^{2}$, Silvana Santos da Cruz ${ }^{3}$
}

\begin{abstract}
Resumo: O presente artigo busca através de conceitos do planejamento de negócio explanar a importância da utilizaçáo da modelagem no desenho e organização das açôes essenciais da empresa, focando o mercado de moda de Cuiabá. Na etapa inicial realizou-se a partir da técnica de estudos de casos múltiplos a definição do modelo de três empresas representativas do setor de varejo de moda em Cuiabá organizando o modelo de negócio de cada uma, utilizando-se da ferramenta Canvas, para alcançar o desenho prático e funcional de toda a organização e sua atuaçáo no mercado. A segunda fase abarcou um levantamento com o público consumidor de moda do mercado da regiáo compatível com o definido pelas empresas entrevistadas, para detectar a aderência ao modelo de negócio das mesmas. Os resultados alcançados foram a visibilidade de pontos de oferta pelas empresas que são considerados importantes pelo público, mas que ainda necessitam de melhoria, principalmente em relação à qualidade de produtos, de atendimento e compatibilidade desses com a precificação que é oferecida pelo mercado regional.
\end{abstract}

Palavras-chave: Modelagem de negócios. Mercado de moda. Estudo de mercado.

\section{FASHION RETAIL IN CUIABÁ: STUDY OF THE BUSINESS MODEL OF COMPANIES IN THE INDUSTRY AND ADHERENCE TO MARKET EXPECTATIONS}

\begin{abstract}
: this article searches through concepts of business planning to explain the importance of using modeling in the design and organization of the organization's essential actions, focusing on the fashion market in Cuiabá. In the initial stage it was used the technique of multiple case studies to the definition of the business model of
\end{abstract}

1 Bacharel em Administração pela Universidade Federal de Mato Grosso. Administradora em empresa do segmento da moda.

2 Mestrando em Economia pelo PPGE-UFMT. Especialista em Marketing pela UNIC. Bacharel em Administraçáo pela UFMT. Docente do Instituto Federal de Educaçáo, Ciência e Tecnologia de Mato Grosso.

3 Especialista em Gestão Executiva de Negócio pela UNIC. Bacharel em Administração pelo UNIVAG. Técnica Coordenadora de Iniciação Científica do Instituto Federal de Educação, Ciência e Tecnologia de Mato Grosso. 
three companies representative of the fashion retail sector in Cuiabá, by organizing the business model of each one, using the Canvas tool, to achieve the Practical and functional design of the entire organization and its performance in the market. The second phase included a survey with the fashion consumer market of the region compatible with the one defined by the companies interviewed, to detect adherence to the business model of the same ones. The results achieved were the visibility of supply points by companies that are considered important by the public, but still need improvement, especially in relation to the quality of products, service and compatibility of these with the pricing that is offered by the regional market.

Keywords: Business modeling. Fashion market. Market research.

\section{INTRODUÇÁO}

Diante das constantes mudanças nos ambientes econômicos, sociais e políticos, cada vez mais se faz necessário que as organizaçóes elaborem estratégias para melhor se desenvolverem e obterem sucesso. Para que isso seja possível é imprescindível um adequado planejamento que as faça cumprir suas metas e objetivos. Nesse sentido, o planejamento estratégico pode ser definido como um processo administrativo que proporciona um maior grau de interação interna e externa, tal como uma ferramenta de gestâo que aponta os caminhos a serem seguidos pelas empresas, fazendo com que elas se mantenham no mercado.

O estudo em questão utilizou-se de teorias e ferramentas do Planejamento Estratégico, o qual leva a empresa à busca de sistematizar e formalizar o pensamento estratégico, conhecendo os caminhos e procedimentos adequados que devem ser seguidos para alcançar o sucesso da estratégia desenhada para o negócio (FERNANDES; BERTON, 2012). Essa formalização ocorreu em forma da utilização de Modelagem de Negócios, conceito esse aplicado e testado em diversas organizações.

No que se refere ao estudo do varejo de Moda, utiliza-se da experiência de empresários representantes das lojas participantes e como eles definem a Moda e o que o seu negócio tem buscado oferecer para o público consumidor desse ramo na regiáo de Cuiabá. A relaçáo entre funcionamento de mercado e Moda tem início na indústria, no próprio processo de confecçóes, e vai além chegando ao varejo, que é onde os fatores emocionais e racionais se unem induzindo o consumidor a possuir aquilo que sente necessidade e desejo, passando por um processo de escolha onde se analise, seleciona e organiza aquilo que lhe convém, interpretando informaçóes de sua personalidade e criando no consumo de moda a imagem que ele possui do mundo em que vive (COBRA, 2007).

Tem-se como objetivo geral do estudo a comparação do modelo de negócio construído, utilizando a ferramenta Canvas de cada empresa entrevistada com a demanda dos consumidores do mesmo segmento. E como objetivos específicos: Identificar o Modelo de Negócio Canvas de três empresas do segmento de moda da cidade de Cuiabá; pesquisar junto aos consumidores de moda quais perspectivas do Modelo de Negócio Canvas relativos a Valor, Relacionamento, Canais de Venda e Receitas, mais lhes interessam e avaliar a aderência dos Modelos de Negócio com a opinião do público.

Tendo em vista os dois parâmetros de Planejamento Estratégico e o mercado de Moda, o trabalho em seu todo se compromete-se em desenvolver primeiramente, através de abordagem qualitativa, o desenho do mapa da modelagem de negócios com a ferramenta Canvas de cada caso estudado, visando identificar o público alvo do negócio em questáo, 
qual sua oferta de valor para o público e como se comunica com ele. Posteriormente, por meio do levantamento quantitativo com pessoas do público alvo definido, responder: qual o nível de compatibilidade de suas necessidades demandadas com a oferta que está sendo colocada no mercado por essas empresas?

Para melhor entendimento o trabalho contempla uma breve revisão teórica sobre a definição de negócio sob a perspectiva do planejamento estratégico e a respeito de modelagem de negócios e a ferramenta Canvas. Seguido dos procedimentos metodológicos utilizados para alcance dos resultados e os próprios resultados obtidos através desta pesquisa.

O estudo permitiu a identificação de resultados que podem impactar na qualidade de atendimento das empresas do setor de moda de Cuiabá, conscientizando o setor das demandas dos seus clientes e conectando ambos os lados, assim concedendo aos lojistas oportunidades de entregar uma oferta de valor compatível aos seus consumidores. Logo, a pesquisa é um canal de ligação, que permite unir ou mesmo resgatar consumidores e empresas.

Além disso, permite aumentar a demanda ou potencializar a existente, fomentando o movimento comercial devido ao encontro da oferta de valor dessas lojas com o desejo relevado pelo mercado, aumentando assim a movimentação econômica desse setor de suma importância para o mercado no cenário regional e nacional.

Visa também ressaltar a validade econômica do mercado da moda, que já ocupa posição considerável na economia mundial, que somente no ano de 2014, conseguiu movimentar US\$ 1,4 trilhão no mundo todo (PALHARES, 2015). Assim, leva a motivar uma discussão para possível implantação do curso de Moda na Universidade Federal de Mato Grosso ou até mesmo a implementação de setores de estudo na faculdade de Administração a respeito do setor.

\section{A DEFINIÇÃO DO NEGÓCIO SOB A PERSPECTIVA DO PLANEJAMENTO ESTRATÉGICO}

O planejamento estratégico é a área da administração responsável pela discussão da análise e formulação da ação estratégica a ser tomada pela organização, é uma parte dentro da Administração Estratégica que, como um todo, envolve não somente o planejamento, mas é um processo mais amplo de execução e controle do que fora previamente determinado pelo Planejamento, trazendo o processo de implementação e gestão das açôes estratégicas (FERNANDES; BERTON, 2012). Em uma pesquisa realizada pela Management Tools and Trends (2015), que desde de 1993 fazem entrevistas com executivos de todo o mundo sobre gerenciamento de ferramentas, apresenta o processo de Planejamento Estratégico em quarto lugar, no ranking mundial das ferramentas mais utilizadas (RIGBY; BILODEAU, 2015).

O processo de Planejamento Estratégico demonstra-se como um dos mais presentes e efetivos instrumentos da administração, em grandes organizações que buscam parâmetros aos decidirem a respeito de suas estratégias, os objetivos e metas a serem alcançados e a programação das açóes que serão desenvolvidas para bem alcançá-los, apesar de receber algumas críticas. Dentre elas, a de Mintzberg (1994 apud NEIS et al., 2017), sendo a 
dificuldade na implementação das estratégias em decorrência da separação entre formulação e implementação das mesmas.

$\mathrm{O}$ conceito de estratégia começou a ser trabalhado em termos militares quando desenvolviam táticas de combate para vencer os inimigos. Esses conceitos começaram a se desenvolver e foram incorporadas aos métodos de gestão após a Segunda Guerra Mundial, mas não se absteriam a somente "vencer o inimigo", e sim a construir futuros desejados e meios de se alcançá-los (FERNANDES; BERTON, 2012). A estratégia vem passando por aperfeiçoamentos e nunca teve uma definição única, possui uma amplitude e complexidade que nunca permitiram que seu conceito fosse estático. (DESS; LUMPKIN; EISNER, 2007)

É essencial que um administrador foque na criação de uma estratégia para que, ao desenvolver de seu caminhar na organização, não se encontre despreparado, ou minimamente seguro do que está por encontrar em sua gestão. É de suma importância que o mesmo crie estratégias, adapte-as à sua realidade e à iminentes mudanças e reformule aquilo que for necessário para que consiga assumir controle do destino da organizaçáo e ter a habilidade de enxergar ameaças transformá-las em oportunidades. Além de estar preparado, o administrador que segue conectado à uma estratégia bem estudada e formulada, é mais favorável a pensar a longo prazo, disciplinar o andamento da organização e ser capaz de ter a seguridade de desenvolver a interação da empresa com o meio e as negociaçóes que esta irá desempenhar, é estar alinhado à um objetivo e promover a mudança que venda ideias (FERNANDES; BERTON, 2012).

Para Kaplan e Norton (2008), a importância da estratégia pode ser explicada pela necessidade de alguns tópicos que toda empresa deve definir para que se possa alcançar a implementação da mesma em suas atividades. Os principais tópicos são:

a) Assumir o controle sobre o destino

b) Enxergar oportunidades

c) Transformar ameaças em oportunidades

d) Definir novos rumos para a organização

e) Introduzir a disciplina de pesar no longo prazo

f) Desenvolver um processo educacional e incentivar a interação e a negociação

g) Mobilizar recursos para o objetivo comum

h) Promover a mudança

i) Vender ideias

Com a análise e planejamento de estratégias a serem seguidas, o administrador, durante o processo de planejamento estratégico, constrói a definição também do que será entregue à sociedade por meio de sua organização, define o seu negócio e o que a sua empresa oferecerá aos seus consumidores, através do Plano de Negócios.

O Plano de Negócios é a descrição do caminho a ser traçado pelo empreendedor na busca de desenvolver seu negócio e/ou empresa, é um documento que descreve por escrito os objetivos de um negócio e quais passos devem ser dados para que esses objetivos sejam 
alcançados, diminuindo os riscos e as incertezas, permite identificar e restringir seus erros no papel e não cometê-los no mercado (SEBRAE, 2013).

Também utilizado para descrever do que o empreendimento em questão se trata, o Plano de Negócios é um documento que sustenta a empresa (DORNELAS, 2005), bem como auxiliar a gerência do negócio e trabalhar no seu sucesso (BANGS, 2002). Dentro da elaboração de um Plano de Negócios, é fundamental que se crie o Modelo de Negócio da empresa e/ou empreendimento em questão. O Modelo de Negócio é uma ferramenta que quando utilizada auxilia no bem fazer da construção do plano, conforme Pigneur e Osterwalder (2011), é pela elaboração de um Modelo de Negócio que a lógica de criação, entrega e captura de valor a ser ofertado pela organização serão descritas. Ainda para os mesmos autores, o Modelo de Negócios é um esquema para a estratégia ser implementada através de estruturas organizacionais dos processos e sistemas.

Teece (2010), destaca que o Modelo de Negócios fornece dados e outros indícios que demonstram como uma empresa cria e entrega valor aos clientes, além disso, descreve a arquitetura das receitas, custos e lucros associados a empresa.

Juntamente com a definição de negócio, virão a definição de outros conceitos que nortearão a ação da empresa dentro do mercado, para Kaplan e Norton (2008), é preciso chegar a um acordo também sobre o propósito, a Missão da organização, sobre a bússola interna que norteará suas açóes, que é o conceito de Valores, e sobre as aspiraçóes quanto aos resultados futuros que se espera, presentes no conceito de Visão da organização.

Definir o propósito de vida da empresa e qual a sua função em seu mercado de atuação é fundamental. A discussão de missão se deve à uma descrição breve que define a razão de ser da organização (KAPLAN; NORTON. 2008), é especificar os negócios que a empresa quer investir e quais segmentos de clientes irá atender (HITT; IRELAND; HOSKISSON, 2008). Em suma, é a resposta para a pergunta "para que existimos?" e que dará sentido ao cotidiano da empresa (FERNANDES; BERTON, 2012).

O propósito da visão organizacional é o de declarar o que a empresa define por objetivos de médio e longo prazo e expressar de forma visionária como quer ser vista pelo mercado (KAPLAN; NORTON, 2008.). Outra definição é a de que a visão busca para a empresa retratar as suas pretensóes do que quer ser e do que pretender realizar (HITT; IRELAND; HOSKISSON, 2008). A pergunta que a organização deve responder para obter seu conceito de visão é "aonde queremos chegar?" e assim explicitar o que se idealiza para aquela organização (FERNANDES; BERTON, 2012). Os valores da empresa devem prescrever suas atitudes, comportamentos e caráter (KAPLAN; NORTON, 2008.).

\subsection{Modelagem de Negócios e a Ferramenta Canvas}

Segundo Pigneur e Osterwalder (2011), um Modelo de Negócios pode ser melhor descrito quando dividido em nove componentes básicos, que mostrem a lógica de como uma organização pretende gerar valor, esses nove componentes cobrem as quatro áreas principais de um negócio, que são os clientes, a oferta, a infraestrutura e a viabilidade financeira. Esses nove componentes são de um Modelo de Negócios formam a base para uma ferramenta chamada Canvas de Modelo de Negócios, esta ferramenta se assemelha 
uma tela de pintura - mas pré-formatada com nove blocos - que permite criar imagens de Modelos de Negócios novos ou já existentes. É uma ferramenta prática e útil que promove entendimento, discussão, criatividade e análise.

Os nove componentes do modelo Canvas cobrem as quatro principais áreas de um negócio: clientes, oferta, infraestrutura e viabilidade financeira (OSTERWALDER; PIGNEUR, 2011, p. 15), e são divididos em dois lados da tela, sendo que o lado esquerdo do Canvas descreve sua eficiência e o lado direito descreve o seu Valor. Os nove componentes são:

a) Segmento de Clientes: O componente que define os diferentes grupos de pessoas ou organizaçóes que uma empresa busca alcançar e servir;

b) Proposta de Valor: O componente que descreve o pacote de produtos e serviços que criam valor para um Segmento de Clientes específico;

c) Canais: $\mathrm{O}$ componente que descreve como uma empresa se comunica e alcança seus Segmentos de Clientes para entregar uma Proposta de Valor.;

d) Relacionamento com Clientes: $\mathrm{O}$ componente que descreve os tipos de relação que uma empresa estabelece com Segmentos de Cliente específico;

e) Fontes de Receita: O componente que representa o dinheiro que uma empresa gera a partir de cada Segmento de Clientes;

f) Recursos Principais: $O$ componente que descreve os recursos mais importantes exigidos para fazer um Modelo de Negócio funcionar;

g) Atividades-chave: $\mathrm{O}$ componente que descreve as açóes mais importantes que uma empresa deve realizar para fazer seu Modelo de Negócio funcionar;

h) Parcerias Principais: $O$ componente que descreve a rede de fornecedores e os parceiros que póem o Modelo de Negócio para funcionar;

i) Estrutura de Custo: O componente que descreve todos os custos envolvidos na operação de um Modelo de Negócio. 
Figura 1: Processo de Construção da Estratégia em uma organização

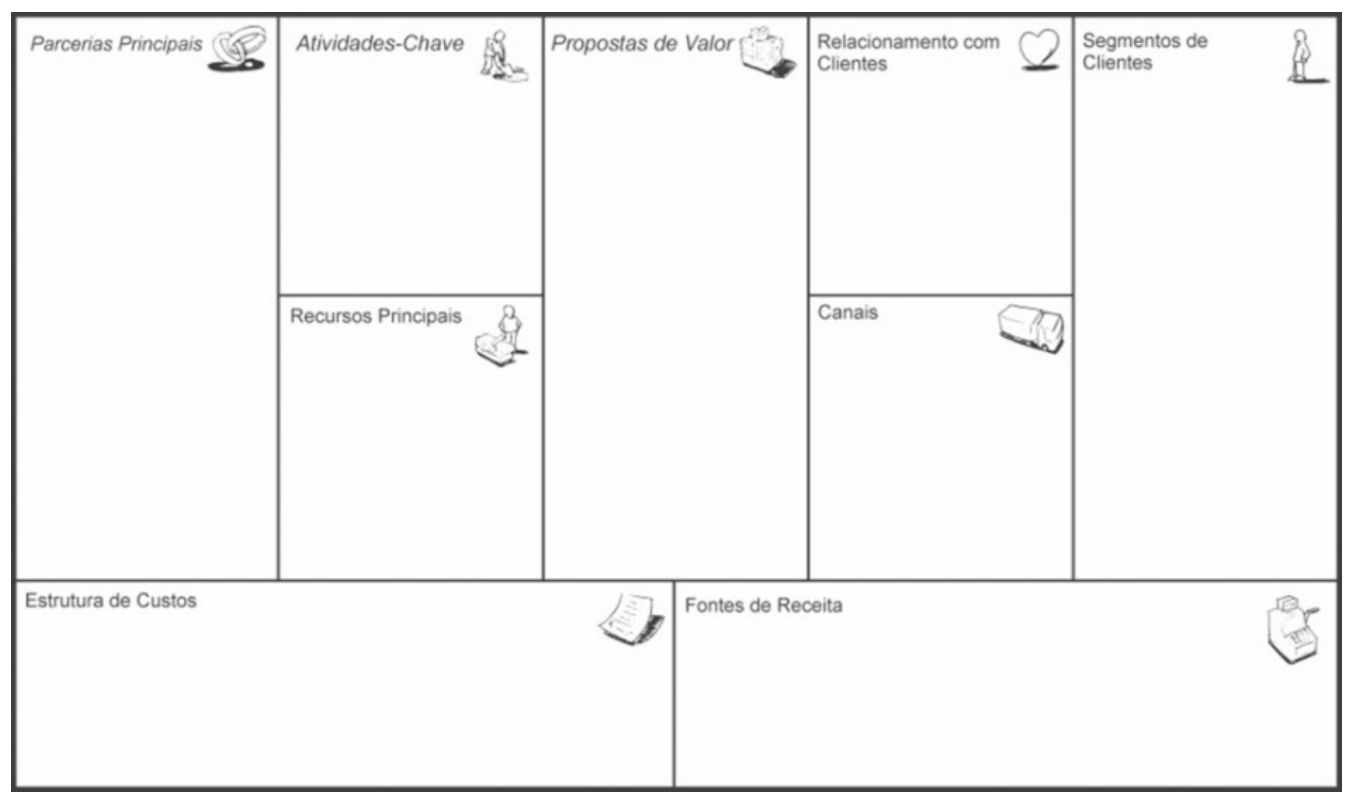

Fonte: Pigneur e Osterwalder, 2011, p. 44.

De acordo com Zott e Amit (2010), o modelo de negócio é uma decisão chave para um novo empresário, e uma tarefa crucial, até mesmo difícil para os gestores encarregados de repensar um modelo, com o propósito de se adequar ao futuro.

Por esse motivo, a utilização do BMC (Business Model Canvas) se torna atrativa à empresários e empreendedores pelo fato de ser prática e de fácil visualização. Em somente uma página é possível desenhar o mapa e descrever as açóes, funçôes e atores das principais áreas da empresa, demonstrando de maneira simples e rápida o panorama geral da organizaçáo. Por isso, é uma maneira inovadora de se escrever o modelo de negócios da empresa e que ganha o mercado.

\section{PROCEDIMENTOS METODOLÓGICOS}

A pesquisa conta com uso de procedimentos de métodos mistos, compreendendo assim uma primeira fase de pesquisa qualitativa e segunda fase de pesquisa quantitativa. Usando-se da estratégia sequencial exploratória (CRESWELL, 2007), realizou-se a convergência de dados quantitativos e qualitativos. Para Denzin e Lincoln (2000), a abordagem qualitativa pode ser definida genericamente como a que abrange estudos nos quais se localiza o observador no mundo onde esse mesmo se encontra em um enfoque naturalístico e interpretativo da realidade. Alguns autores também avaliam o método qualitativo como sendo mais atrativo por suas fontes de descriçóes ricas, onde os dados são vívidos e proporcionam maior riqueza de interpretaçóes (MILES; HUBERMAN, 1994).

A primeira fase, de abordagem qualitativa com a técnica de estudo múltiplo de casos, foi realizada com três empresas representantes do varejo de moda segmentadas entre 
clientes de maior renda da região de Cuiabá. Dessa forma utilizou-se como instrumento de coleta de dados um roteiro semiestruturado para entrevista de profundidade com o gestor ou proprietário de cada loja. O instrumento é dividido em dois blocos, um inicial sobre o perfil, a história empreendedora da loja e sobre perspectivas do mercado da moda. $\mathrm{O}$ segundo bloco contém as perguntas necessárias para a construção do modelo de negócio conforme a ferramenta Canvas. As entrevistas foram gravadas e a interpretação foi realizada por meio de análise de seu conteúdo.

A escolha das três empresas foi realizada de modo intencional e não-aleatório, já que utilizou-se como critérios de seleçấo aquelas de maior tradição e ou representatividade no mercado local de moda. Deu-se entáo preferência para as lojas mais antigas e mais solidificadas no segmento local. As lojas foram visitadas in loco, onde as respectivas gestoras ou proprietárias receberam o convite para participação na pesquisa. Os dados das empresas e das entrevistas foram agrupados no quadro a seguir:

Quadro 1 - Síntese da data, tempo de duração e dados dos entrevistados

\begin{tabular}{|l|l|l|l|l|}
\hline $\begin{array}{l}\text { EMPRESA/ } \\
\text { DATA DA } \\
\text { ENTREVISTA }\end{array}$ & $\begin{array}{l}\text { TEMPO DE } \\
\text { DURAÇÃO }\end{array}$ & CARGO & $\begin{array}{l}\text { TEMPO NO } \\
\text { CARGO }\end{array}$ & FORMAÇÃO \\
\hline ALFA & $36 \mathrm{~min} 7 \mathrm{~s}$ & $\begin{array}{l}\text { Diretora de } \\
\text { Marketing/ } \\
\text { Proprietária }\end{array}$ & 2 anos & Ensino Superior \\
\hline BETA & $36 \mathrm{~min} 26 \mathrm{~s}$ & $\begin{array}{l}\text { Diretora } \\
\text { Financeiro/ } \\
\text { Proprietária }\end{array}$ & 5 anos & Ensino Superior \\
\hline GAMA & $54 \mathrm{~min} 38 \mathrm{~s}$ & Proprietária & 32 anos & Ensino Médio \\
\hline $15 / 02 / 2017$ & & & & \\
\hline
\end{tabular}

Fonte: Dados da pesquisa (2017).

A segunda fase da pesquisa, considerada quantitativa, é definida por Creswell (2007), como sendo a que usa primariamente alegaçóes pró positivistas para desenvolvimento de conhecimento e empresa estratégias de investigação, como experimentos, levantamentos e coleta de dados, instrumentos predeterminados, que geram dados estatísticos.

Ainda em relação ao método quantitativo, pode-se dizer que é uma abordagem que se preocupa com a quantificação de dados e se utiliza de recursos e técnicas estatísticas. É comumente utilizada para pesquisas com objetivo descritivo onde se procura descobrir e classificar a relação entre variáveis ou em pesquisas conclusivas, onde se buscam relaçóes de causalidade entre eventos (OLIVEIRA, 1997).

Nessa fase o levantamento é caracterizado com amostragem não probabilística estratificada e estatisticamente não controlada. $\mathrm{O}$ instrumento de coleta de dados utilizado foi um questionário estruturado, com perguntas abertas e fechadas. Esse questionário tratava das questôes ligadas as perceptivas dos Clientes, o que se trata como sendo o "lado direito do Canvas". As questôes visam identificar os atributos mais importantes para os clientes 
no momento da compra, dentre outros itens de comportamento de compra e hábitos de consumo. Os instrumentos de coleta, seja o roteiro ou o questionário quantitativo, foram construídos a partir da síntese da fundamentação teórica.

No caso do instrumento quantitativo, foram utilizadas as respostas da etapa qualitativa no auxílio da construção de questōes que visaram testar as respostas obtidas das três empresas entrevistadas, como nos âmbitos de Proposta de Valor, Canais, Relacionamento com Clientes e Estrutura de Custos. Quanto à classificação da pesquisa, a mesma conta com recorte temporal caracterizado como sendo de corte transversal, que para Cooper e Schindler (2003), é focado em um período de tempo específico e único. Nesse caso as entrevistas foram realizas durante o mês de fevereiro e o questionário aplicado durante fevereiro a março. Utilizou-se para coleta uma ferramenta online gratuita, onde o questionário foi construído e enviado por e-mail e pela Rede Social de Comunicaçâo WhatsApp aos participantes. O quadro abaixo sintetiza o método utilizado na pesquisa e suas fases:

Quadro 2 - Síntese das etapas da pesquisa

\begin{tabular}{|l|l|l|}
\hline \multicolumn{1}{|c|}{ FASE } & \multicolumn{1}{|c|}{$1^{\text {a } \text { etapa }}$} & \multicolumn{1}{|c|}{$2^{\text {a etapa }}$} \\
\hline $\begin{array}{l}\text { Técnica de } \\
\text { pesquisa }\end{array}$ & Estudo de casos múltiplos & Levantamento Quantitativo \\
\hline $\begin{array}{l}\text { Abordagem } \\
\text { do problema }\end{array}$ & $\begin{array}{l}\text { Abordagem qualitativa por meio de } \\
\text { Entrevista com 3 (três) Empresas do } \\
\text { mercado da moda de Cuiabá. }\end{array}$ & $\begin{array}{l}\text { Abordagem quantitativa por meio de } \\
\text { Entrevista com questionário estruturado de } \\
\text { perguntas fechadas, estratificado (pergunta } \\
\text { filtro) com consumidores da moda de } \\
\text { Cuiabá. }\end{array}$ \\
\hline $\begin{array}{l}\text { Método de } \\
\text { pesquisa }\end{array}$ & $\begin{array}{l}\text { Construção de modelo de negócio } \\
\text { de cada empresa utilizando-se da } \\
\text { Ferramenta Canvas. }\end{array}$ & $\begin{array}{l}\text { Construção de escala de satisfação com a } \\
\text { oferta existente e demanda percebida pelo } \\
\text { público em relação ao mercado da moda de } \\
\text { Cuiabá. }\end{array}$ \\
\hline
\end{tabular}

Fonte: Elaborado pelos autores (2017).

\section{APRESENTAÇÃO E DISCUSSÃO DOS RESULTADOS}

Inicialmente apresenta-se uma breve introdução à história de cada organização, denominadas Alfa, Beta e Gama, e posteriormente o Canvas construído a partir das entrevistas.

\subsection{Caso Alfa: Produzir para quebrar barreiras}

A empresa Alfa, atuante na área de confecçōes na cidade de Cuiabá, possui dez anos de mercado e conta com um quadro de cinquenta e sete funcionários. É dividida em dois setores, de varejo de atacado, mas hoje se volta mais para seu crescente e mais rentável setor de atacado. Segundo a gestora, sua máe foi pioneira da empresa quando se desvinculou de outra empresa de confecçóes da família e deu início ao negócio, que focou no início em 
roupas casuais e depois de 5 anos começou a trabalhar com moda festa, encontrando maior sucesso.

A maior dificuldade encontrada pela loja ao longo de seu crescimento no mercado foi, segundo a gestora "a aceitação do público A e B de Cuiabá com as roupas que eram fabricadas aqui, às vezes acham que por ser de São Paulo é melhor”, mas foram conseguindo mostrar que isso não necessariamente acontece. Para a gestora, os três episódios que mais marcaram a loja foram os de quando famosas blogueiras brasileiras utilizaram suas roupas, o que alastrou pelo território brasileiro o nome da empresa e de sua produção, a construção da loja matriz em Cuiabá, onde se localizam a venda para varejo, fábrica e administrativo e a participação na grande feira de moda brasileira, Minas Trend. No quadro 3 se encontra o Mapa de Negócio Canvas, construído a partir das respostas dadas na entrevista, analisando o lado direito que se refere ao valor que a empresa possui é possível perceber que o valor criado pela empresa Alfa se dá através da oferta de produtos exclusivos, personalizados e de qualidade produzidos localmente.

\subsection{Caso Beta: Expandir rumo as grandes marcas}

Empresa atuante na área de luxo com a revenda de grandes marcas, com cinco anos de atuaçáo no mercado teve, a gestora inicia explicando que a história da loja foi marcada pelo inesperado crescimento de demanda do público cuiabano, o que levou à ampliação da loja para que conseguissem atender quem procurava as melhores marcas nacionais em um só lugar. Ela diz que, com a iniciativa diferente do resto do mercado cuiabano, apostar no mercado de luxo com somente uma marca renomada no Brasil deu muito certo, e acabou fazendo com que expandissem para mais marcas e conquistassem um mercado que fiel, conforme o resultado da pesquisa:

O que era para vender em seis meses, nós vendemos em dois, a gente ficou sem estoque, [...] tivemos que expandir nossa loja em tempo recorde, a gente achou que ia conseguir ficar somente com dois pisos, mas fomos praticamente obrigados a agregar marcas, foi uma coisa que surpreendeu a gente, não esperávamos esse "bum" na loja.

A visão de mercado da entrevistada é a de que todo mundo gosta de moda e todo mundo consegue ter acesso, olhando dentro de sua loja ela firma que as pessoas gostam e procuram moda, o que tem de mais novo e moderno, querem sempre o lançamento, ninguém procura aquilo que já tenha passado. As pessoas querem o que tem de mais novo, o que foi surpreendente para a gestora. Os pontos fracos e fortes para a empresa nesse mercado definidos pela gestora são de que, segundo dados da obtidos na pesquisa:

Você não pode parar nunca, tem que acompanhar a moda, lançou você tem que estar junto, se não fica para trás. O ponto forte é que as pessoas sempre vão comprar, nunca vão deixar de comprar.

Em relação ao perfil de público consumidor de moda, a gestora afirma que todos se encaixam, já que "todo mundo compra moda, todo mundo gosta, aqui (na loja) entra todo 
mundo", o que ela afirma ter dificuldades ao estabelecer um único perfil de compradores é que, de acordo com a fala transcrita:

\section{Quadro 3 - Mapa de Negócio Canvas - Empresa Alfa}

\begin{tabular}{|c|c|c|c|c|}
\hline \multirow[t]{2}{*}{$\begin{array}{l}\text { Parceiros } \\
\text { - Correios } \\
\text { - Bordadeiras } \\
\text { (terceirizado) } \\
\text { - Fornecedores de } \\
\text { tecido (São Paulo) }\end{array}$} & $\begin{array}{l}\text { Atividades Chave } \\
\text { - Capacitaçấo em } \\
\text { entender o sonho da } \\
\text { cliente e transmitir } \\
\text { para roupas } \\
\text { - Capacitaçâa em } \\
\text { conhecimento de } \\
\text { moda } \\
\text { - Harmonia do eixo } \\
\text { fábrica/vendedoras/loja } \\
\text { - Processo de } \\
\text { Confecção }\end{array}$ & \multirow[t]{2}{*}{$\begin{array}{l}\text { Oferta de Valor } \\
\text { - Personalização } \\
\text { - Exclusividade } \\
\text { - Qualidade } \\
\text { - Preço justo } \\
\text { - Bordados feito a mão } \\
\text { - Produçáo local - } \\
\text { fábrica à disposição } \\
\text { para modificaçôes e } \\
\text { ajustes } \\
\text { - Honestidade - saber } \\
\text { oferecer a roupa ideal }\end{array}$} & $\begin{array}{l}\text { Relacionamento } \\
\text { com clientes } \\
\\
\text { - Facebook } \\
\text { - Instagram } \\
\text { - WhatsApp }\end{array}$ & \multirow[t]{2}{*}{$\begin{array}{l}\text { Segmento de Cliente } \\
\text { - 100\% Mulheres } \\
\text { - Classe B e C } \\
\text { - Procuram diferencial } \\
\text { em roupas de festa } \\
\text { - Pessoas seguras } \\
\text { financeiramente } \\
\text { (Servidor Público) }\end{array}$} \\
\hline & $\begin{array}{l}\text { Recursos Chave } \\
\text { - Atualização constante } \\
\text { de redes sociais } \\
\text { (postagem de fotos no } \\
\text { Instagram) } \\
\text { - Profissionalismo } \\
\text { (equipe qualificada) } \\
\text { - Dedicação no } \\
\text { atendimento e no } \\
\text { gerenciamento das } \\
\text { redes sociais }\end{array}$ & & $\begin{array}{l}\text { Canais } \\
\text { - Loja Física } \\
\text { - Loja Virtual } \\
\text { - WhatsApp }\end{array}$ & \\
\hline \multicolumn{5}{|l|}{$\begin{array}{l}\text { - Mão de obra } \\
\text { - Matéria Prima }\end{array}$} \\
\hline
\end{tabular}

Fonte: Dados da pesquisa (2017).

As pessoas tem medo de entrar aqui, acham que tudo é caro, mas de um tempo para cá a gente começou a adotar uma outra estratégia de marketing, para quem tinha medo, então hoje, todo mundo já consegue entrar aqui, das pessoas que entram a gente atende todo mundo, e todo mundo consegue comprar, porque a gente tem uma calça jeans de $\mathrm{R} \$ 100,00$, e nós temos calça de $\mathrm{R} \$ 1.000,00$. É questão de gosto, e aqui dentro da loja é tudo separado por marcas, entáo quando a gente vai atender um cliente de vestido de festa por exemplo, as vendedora tem um manual, elas estudaram para fazer $o$ atendimento, tem que saber quanto que o cliente quer investir em uma roupa, você jamais mostra para uma cliente um vestido todo bordado de $\mathrm{R} \$ 10.000,00$ se ela só quer investir $\mathrm{R} \$ 1.000,00$. [...] Então acho que não tem um público específico, a gente consegue atender todo mundo.

Neste caso ficou evidente o uso da estratégia por parte da gestora da empresa, conforme já mencionado anteriormente por Kaplan e Norton (2008), para que seja possível sua implementação nas atividades de um negócio se faz necessário o uso de alguns tópicos, no caso da empresa Beta o primeiro tópico utilizado foi o de assumir o controle sobre o destino, em que mesmo diante de uma situaçáo inesperada, como o crescimento da 
demanda, a empresa conseguiu a partir disso enxergar uma oportunidade, realizando assim a expansão da loja e dos produtos ofertados.

\subsection{Caso Gama: Oferecendo o diferente para conquistar}

A empresa iniciou suas atividades há 32 anos, uma das mais antigas da cidade, a gestora, porém, já trabalha com o mercado de moda há 34 anos. Ela conta que no início vendia roupas através de visitas de porta em porta à suas clientes, visando sempre peças diferentes e únicas, e que o início desse negócio se deu mais pela necessidade de um trabalho, ao se mudar de cidade e vir para Cuiabá, e pela paixão por vendas do que pela sua atração pelo mercado de moda em si, que cresceu ao passar do tempo, conforme a fala transcrita:

Eu vejo como uma empresa expressiva no sentido do diferencial. Eu iniciei há 32 anos
atrás, devagar, pequena mesmo, vendendo roupa de porta em porta, montei loja no fundo
da minha casa, hoje eu vejo ela representativa no sentido de quantidade de funcionários, na
forma como que ela cresceu, essa coisa mais firma, mais sólida. A grande representatividade
que eu vejo é o diferencial, tanto de produto quanto de serviço que a gente tem para
oferecer.

Vendendo marcas diferentes e um produto especial, atualmente a loja é, para a gestora, sinônimo de um produto diferenciado, já que segunda ela "o que tem de melhor na moda nacional está sendo oferecido pela loja”. Segundo dados da pesquisa:

Quando eu fazia a venda de porta em porta eu sempre tive o cuidado de o que vender, eu não queria aquilo que você encontrasse em qualquer lugar, eu queria o diferente, uma coisa mais especial, por isso o sucesso do crescimento, principalmente o inicial, porque eu vendia produtos diferenciados. [...] Quando eu abri a loja física eu comecei a viajar muito para fora porque eu queria apresentar e trabalhar de uma forma diferente de tudo que eu via no mercado, principalmente aqui de Cuiabá. [...] Não é como se fosse "nossa eu abri uma empresa de informática porque me formei em informática ou algo parecido", não, eu comecei dessa forma e fui me apaixonando cada vez mais, o que mais me apaixona, o que eu amo fazer, é a arte de vender. [...] Para se ter uma noção, eu tenho cliente hoje na loja que era cliente minha de quando eu vendia roupas na casa dela, isso é uma coisa gostosa.

As dificuldades no início da loja para a gestora foram inexistentes se comparadas ao momento atual, afirma que a burocracia e a forma hoje que o empresário tem para trabalhar são maiores do que há 32 anos atrás, principalmente com uma quantidade bem maior de funcionários. Para ela, o custo de se manter uma loja é mais difícil.

Durante a história da loja a gestora relembra dois marcos importantes para o funcionamento de sua loja, sendo a instabilidade financeira da população quando ocorreu o Plano Collor em 1994 e a perda de seu esposo, que era gestor da loja desde o início ao seu lado, conforme a fala transcrita:

Foi um período muito tumultuado (Plano Collor), você não sabia se fechava a loja, se pagava (a mercadoria), como que pagava, foi muito marcante. [...] Durante esses trinta anos cada mandato foi uma surpresa pra gente. 
A gestora explica que os consumidores de moda que conhecem tendências e se importam em adquirir o que está sendo ditado no "mundo da moda" tem um perfil extremamente exigente, mas que esses ainda formam um nicho pequeno em comparação aos consumidores que buscam por produtos da moda mas que não se importam com as tendências que foram expostas nos desfiles internacionais e o que ditam os conceitos mundiais de moda, ela explica que esse nicho pequeno e exigente é o que deseja consumir exatamente aquilo que foi apresentado nas passarelas e desfiles, e que esse é um consumidor difícil de agradar.

\section{Quadro 4 - Mapa de Negócio Canvas - Empresa Beta}

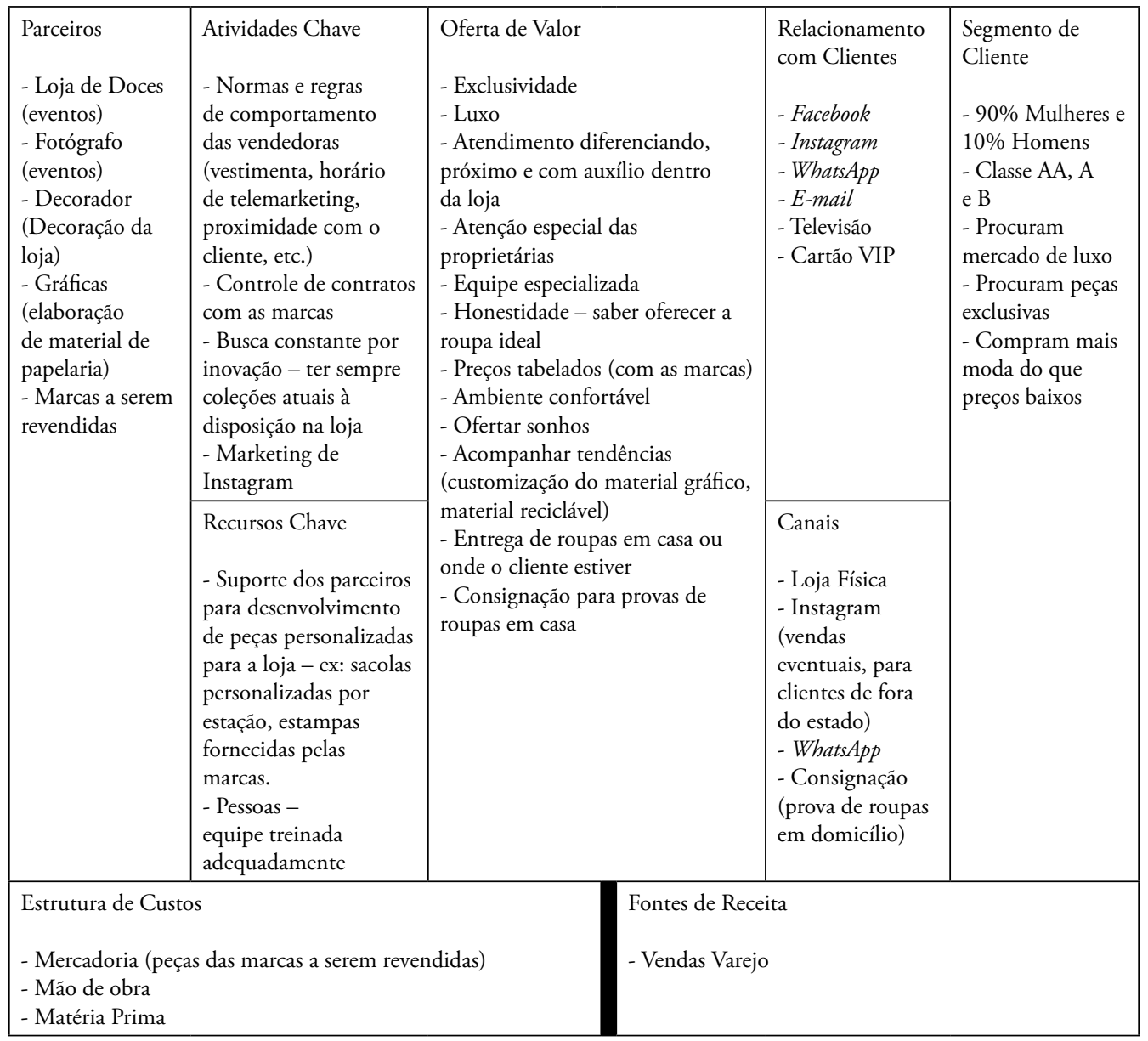

Fonte: Dados da pesquisa (2017). 
Quadro 5 - Mapa de Negócio Canvas - Empresa Gama

\begin{tabular}{|c|c|c|c|c|}
\hline \multirow[t]{2}{*}{$\begin{array}{l}\text { Parceiros } \\
\text { - Fornecedores } \\
\text { - marcas } \\
\text { revendidas } \\
\text { - Empresas } \\
\text { que auxiliam } \\
\text { na construção } \\
\text { de eventos } \\
\text { (concessionárias } \\
\text { de veículos e } \\
\text { gráficas) } \\
\text { - Funcionários } \\
\text { - Clientes }\end{array}$} & $\begin{array}{l}\text { Atividades Chave } \\
\text { - Tarefas diárias - } \\
\text { conferência de roupas } \\
\text { a serem pedidas e que } \\
\text { foram solicitadas por } \\
\text { clientes } \\
\text { - Recebimento de novos } \\
\text { produtos, cadastramento } \\
\text { e baixa } \\
\text { - Estar em sintonia com } \\
\text { a necessidade do cliente } \\
\text { - Ter produtos que sejam } \\
\text { novidade - manter o } \\
\text { ritmo de tendências e } \\
\text { novas peças }\end{array}$ & \multirow[t]{2}{*}{$\begin{array}{l}\text { Oferta de Valor } \\
\text { - Peças únicas e diferentes } \\
\text { - Passar encantamento } \\
\text { - Bem-estar e alegria ao comprar } \\
\text { - Venda de sonhos } \\
\text { - Atendimento próximo e } \\
\text { atencioso } \\
\text { - Conhecer o perfil do cliente } \\
\text { - Marcas exclusivas } \\
\text { - Integração espaço e } \\
\text { atendimento } \\
\text { - Necessidades atendidas na loja } \\
\text { - ateliê de costura à disposição }\end{array}$} & $\begin{array}{l}\text { Relacionamento } \\
\text { com Clientes } \\
\text { - Facebook } \\
\text { - Instagram } \\
\text { - WhatsApp } \\
\text { - Telefone } \\
\text { - Mensagens de } \\
\text { Texto }\end{array}$ & \multirow[t]{2}{*}{$\begin{array}{l}\begin{array}{l}\text { Segmento de } \\
\text { Cliente }\end{array} \\
\text { - 100\% Mulheres } \\
\text { - Classe AA, A } \\
\text { e B } \\
\text { - Exigentes } \\
\text { - Querem o } \\
\text { diferencial em } \\
\text { moda }\end{array}$} \\
\hline & $\begin{array}{l}\text { Recursos Chave } \\
\text { - Equipe de venda } \\
\text { - Equipe Administrativa } \\
\text { - Equipe de costura } \\
\text { (ateliê) } \\
\text { - Espaço adequado e que } \\
\text { suporte a demanda }\end{array}$ & & $\begin{array}{l}\text { Canais } \\
\text { - Loja Física }\end{array}$ & \\
\hline $\begin{array}{l}\text { Estrutura de Cus } \\
\text { - Mercadoria (peç } \\
\text { - Equipe } \\
\text { - Matéria Prima }\end{array}$ & das marcas a serem reven & $\begin{array}{l}\text { Fontes de Receita } \\
\text { - Vendas Varejo }\end{array}$ & & \\
\hline
\end{tabular}

Fonte: Dados da pesquisa (2017).

\subsection{Apresentaçáo dos dados quantitativos do mercado local de consumidores de moda}

Durante a investigação, responderam ao questionário 125 pessoas, das quais, após filtragem apenas 86 se encaixaram na categoria de Segmento de Clientes definida na elaboração dos Modelos de Negócios na etapa qualitativa, levando em consideração a porcentagem de Sexo e a Renda para classificação de classe social. Logo, as respostas consideradas para a elaboração da análise quantitativa são somente aquelas aderentes ao segmento definido pelos casos.

As três empresas entrevistadas classificaram seu público alvo, no geral, como sendo pertencentes aos públicos de classe AA, A, B e C, para o tanto, a pesquisa também segmentou os respondentes de acordo com a Renda estabelecida, sendo considerados somente os que possuem renda acima de $\mathrm{R} \$ 2.705,00$, o que é classificatório para encaixe nas classes acima citadas. 
Quadro 6 - Descriçấo do perfil dos respondentes

\begin{tabular}{|l|c|}
\hline Variáveis & Resultado Geral \\
\hline Sexo & \\
\hline Masculino & $12,8 \%$ \\
\hline Feminino & $87,2 \%$ \\
\hline Idade & \\
\hline De 18 a 25 anos & $25,6 \%$ \\
\hline De 25 a 35 anos & $12,8 \%$ \\
\hline De 35 a 45 anos & $30,2 \%$ \\
\hline De 45 a 55 anos & $26,7 \%$ \\
\hline Acima de 55 anos & $4,7 \%$ \\
\hline Atuação Profissional & \\
\hline Empresário(a) & $12,8 \%$ \\
\hline Profissional do Setor Público & $30,2 \%$ \\
\hline Autônomo(a) & $8,1 \%$ \\
\hline Prestador(a) de Serviços & $3,5 \%$ \\
\hline Estudante & $14,0 \%$ \\
\hline Profissional do Setor Privado & $8,1 \%$ \\
\hline Do lar & $9,3 \%$ \\
\hline Aposentado & $2,3 \%$ \\
\hline Profissional Liberal & $11,6 \%$ \\
\hline Nível de Escolaridade & \\
\hline Ensino Fundamental & $0,0 \%$ \\
\hline Ensino Médio & $12,8 \%$ \\
\hline Ensino Superior & $45,3 \%$ \\
\hline Pós Graduação & $41,9 \%$ \\
\hline Estado Civil & \\
\hline Casado(a) & $53,5 \%$ \\
\hline Solteiro(a) & $29,1 \%$ \\
\hline Divorciado(a) & $5,8 \%$ \\
\hline Viúvo(a) & $5,8 \%$ \\
\hline Separado(a) & $1,2 \%$ \\
\hline Companheiro(a) & $4,7 \%$ \\
\hline Renda & $25,6 \%$ \\
\hline Entre R\$ 2.705,00 e R\$ 4.851,99 & \\
\hline Entre R\$ 4.852,00 e R\$ 9.253,99 & \\
\hline Entre R\$ 9.254 e R $20.887,99$ & \\
\hline Acima de R $\$ 20.888,00$ & \\
\hline
\end{tabular}

Fonte: dados da pesquisa (2017). 
Em relaçáo aos produtos que foram adquiridos quantificou-se se observando a predominância de Calças (64), Blusas (62) e Vestidos Casuais (48). Verifica-se a característica de um público que está comprando produtos diários, que são utilizados em ocasiôes casuais, um perfil consumidor de produtos do dia-a-dia, garantindo a utilização de produtos da moda diariamente. Com uma boa distribuiçáo entre as quantias de gastos, o público entrevistado demonstra suas maiores porcentagens em faixas altas de gastos, sendo que $15,1 \%$ dos respondentes gastaram entre $\mathrm{R} \$ 3.000,00$ e $\mathrm{R} \$ 5.000,00$, o que em média representa em média gasto de $\mathrm{R} \$ 666,60$ por mês em produtos de moda, demonstrando que o alto poder aquisitivo dos respondentes corresponde ao desejo de consumo de produtos de moda e a importância em reservar parte considerável de sua renda para esses produtos.

Em proporção, quando se segmentam os resultados por sexo, é nítida a diferença entre os valores gastos entre mulheres e homens, sendo que o público feminino se distribui mais em suas faixas de gastos, tendo sua maioria concentrada nas faixas entre $\mathrm{R} \$ 3.000,00$ e R\$5.000,00. Já o público masculino compreende sua maioria na faixa de gastos entre $\mathrm{R} \$ 750,00$ e $\mathrm{R} \$ 1.000,00$, valor baixo se comparado às mulheres, mas ainda sim possui respondentes expressivos que consumiram valores acima de $\mathrm{R} \$ 2.000,00$, o que mostra um público mais restritivo aos gastos em relação ao público feminino em sua maioria.

Em relação à satisfação com o custo-benefício desses produtos, o público se mostrou ainda insatisfeito. Com uma média de 2,20 é possível observar que os respondentes não se sentem atraídos pela precificaçáo oferecida na regiáo aos produtos de moda, nota-se que a maior parte dos respondentes está nos níveis de insatisfaçấo, com $67 \%$ desses se declarando pouco e muito insatisfeitos. Em comparação, a satisfação é quase insignificante, com apenas $12 \%$ dos respondentes se declarando muito ou apenas satisfeitos com esse custo-benefício. Em relação aos itens da Oferta de Valor descritos na etapa qualitativa, os atributos de importância demandados pelos entrevistados foram relacionados no quadro a seguir:

Quadro 7 - Itens de importância ao ser oferecido pela loja na hora de escolher a sua loja de moda preferida

\begin{tabular}{|l|c|c|c|}
\hline \multicolumn{1}{|c|}{ ITENS DE IMPORTÂNCIA } & MÉDIA & MEDIANA & DP \\
\hline $\begin{array}{l}\text { Produtos personalizados (ateliê de costura para ajuste e/ou } \\
\text { modificaçóes) }\end{array}$ & 3,12 & 3 & 1,33 \\
\hline Exclusividade de peças & 3,13 & 3 & 1,32 \\
\hline Ajudar o cliente a encontrar o ideal, com sinceridade & 3,97 & 4 & 1,17 \\
\hline Qualidade de tecidos e mão de obra & 4,33 & 5 & 0,98 \\
\hline Preço justo & 4,47 & 5 & 0,99 \\
\hline Preço tabelado com as marcas & 3,57 & 4 & 1,16 \\
\hline Vender roupas e melhorar a autoestima, materializar sonhos & 3,23 & 3 & 1,31 \\
\hline Ter mostruário e peças que acompanhem as últimas tendências & 3,35 & 3 & 1,08 \\
\hline $\begin{array}{l}\text { Material gráfico personalizado (ex: sacolas que sigam as } \\
\text { estaçóes da moda) }\end{array}$ & 2,49 & 3 & 1,32 \\
\hline Preocupação ambiental (ex: sacolas recicláveis) & 3,45 & 4 & 1,33 \\
\hline
\end{tabular}




\begin{tabular}{|l|c|c|c|}
\hline \multicolumn{1}{|c|}{ ITENS DE IMPORTÂNCIA } & MÉDIA & MEDIANA & DP \\
\hline $\begin{array}{l}\text { Venda in loco (levar as roupas até onde estou, casa, trabalho, } \\
\text { saláo, etc.) }\end{array}$ & 2,71 & 3 & 1,34 \\
\hline Consignação para prova de roupas em casa & 2,77 & 3 & 1,44 \\
\hline Produtos inovadores, diferentes, novos & 3,76 & 4 & 1,11 \\
\hline Estilistas renomados e marcas únicas & 2,62 & 2,5 & 1,35 \\
\hline Roupas que encantam pelos detalhes & 3,70 & 4 & 1,24 \\
\hline Roupas que contam história e conquistam a personalidade & 3,18 & 3 & 1,27 \\
\hline Saber entender o cliente e auxiliar na escolha certa & 4,04 & 5 & 1,22 \\
\hline Atençáo especial do(a) proprietário(a) durante a visita na loja & 3,29 & 3 & 1,29 \\
\hline $\begin{array}{l}\text { Proximidade pessoal com a loja, comprar roupas e conversar, } \\
\text { ambiente de lazer }\end{array}$ & 3,36 & 3 & 1,23 \\
\hline $\begin{array}{l}\text { Credibilidade em Moda, conhecer as tendências e repassar ao } \\
\text { cliente }\end{array}$ & 3,63 & 4 & 1,15 \\
\hline Espaço atrativo e confortável & 3,99 & 4 & 1,12 \\
\hline
\end{tabular}

Fonte: Dados da pesquisa (2017).

Os itens com maiores pontuações foram os de "Qualidade de tecidos e mão de obra" $(4,33)$, "Preço Justo" $(4,47)$ e "Saber entender o cliente e auxiliar na escolha certa" $(4,04)$, todos com notas médias acima de 4, acima do nível de concordância. Todos os três itens de maior pontuação foram expostos pelas três empresas como sendo importantes para a conquista de seus clientes durante toda a entrevista, mas somente no Modelo de Negócio Canvas da empresa Alfa é possível visualizar com mais precisão a oferta de "Qualidade de tecidos e mão de obra" e "Preço justo" como sendo itens essenciais para a oferta de valor da empresa, o que demonstra, nas maiores pontuações, maior proximidade da empresa Alfa com a expectativa do público.

Itens com notas abaixo da média de importância podem não significar necessariamente a aversão do cliente àquela oferta, mas sim que não será um item de importância para a sua decisão final do momento da compra, somente algo que ele considere complementar durante o ato de compra, mas não decisivo. Em relação ao teste de aderência aos meios de comunicação propostos pelas empresas entrevistadas, os resultados inferem um alto nível de aderência em relação ao Canvas dos casos. A maior porcentagem das respostas foi da Rede Social Instagram, a qual fora citada pelas três empresas entrevistadas, demonstrando ser um canal de comunicação importante.

Observa-se que as duas maiores porcentagens seguintes também compreendem Mídias Sociais modernas e atuais, que são o WhatsApp, com 21\% e o Facebook, com $14 \%$ das respostas. Mesmo sendo pouco expressivo, ainda existe o público que prefere se comunicar com as lojas através das mídias tradicionais, o que somente a empresa Gama explicitou ser uma atividade ainda em uso nos seus Canais de Comunicação, e que pode ser uma vantagem ao atingi-los. 
Gráfico 1 - Preferência de canais de venda da loja de moda na região de Cuiabá

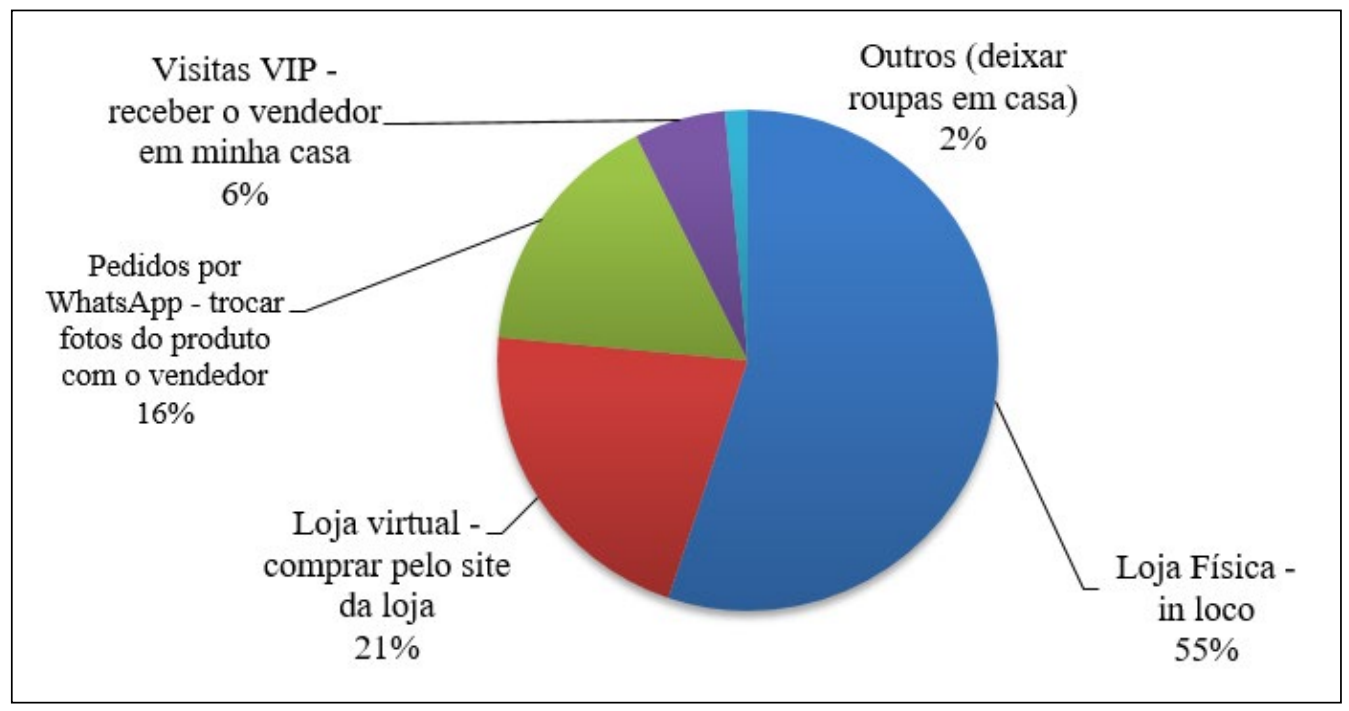

Fonte: dados da pesquisa (2017).

A preferência pela visita na loja física é dominante nessa etapa da pesquisa, com $55 \%$ das respostas, é notável que o público de moda de Cuiabá ainda busca por visitas, onde possa despender um pouco de seu tempo para fazer suas escolhas, se deslocando ao local, ao observar a modelagem de negócio das três empresas entrevistadas, nota-se que todas possuem espaço físico para atendimento de seus clientes. Isso denota que os clientes valorizam o controle e a proximidade durante a compra. Os meios virtuais também são resultados consideráveis, tendo a Loja Virtual $21 \%$ de preferência e o uso do WhatsApp $16 \%$ de preferência, é possível perceber características de um público que busca maior conforto e praticidade ao escolher seus produtos de moda e que valoriza os meios digitais para realizar compras, o que ainda não está sendo utilizado completamente pelas empresas Beta e Gama, que não contam com a plataforma virtual de compra pelo site da loja, apesar de efetivarem operaçóes pela mídia social Instagram e pelo WhatsApp. A visita VIP, onde o vendedor é recebido em casa, não foi preferência ficou com apenas $6 \%$ das respostas.

Quadro 8 - Hábitos de Consumo do mercado de varejo de moda da região de Cuiabá

\begin{tabular}{|l|c|c|c|}
\hline \multicolumn{1}{|c|}{ HÁBITOS } & MÉDIA & MEDIANA & $\begin{array}{c}\text { DESVIO } \\
\text { PADRÁO }\end{array}$ \\
\hline $\begin{array}{l}\text { Procuro sempre o menor preço, independente dos detalhes } \\
\text { do produto }\end{array}$ & 2,50 & 2 & 1,07 \\
\hline $\begin{array}{l}\text { Náo pergunto preço quando quero comprar um item de } \\
\text { moda, escolho aquilo que gosto e pago o que for preciso }\end{array}$ & 2,37 & 2 & 1,19 \\
\hline Faço pesquisa de mercado em várias lojas antes de comprar & 2,95 & 3 & 1,36 \\
\hline Faço pesquisa na Internet para comparar preços das marcas & 3,09 & 3 & 1,39 \\
\hline
\end{tabular}




\begin{tabular}{|l|c|c|c|}
\hline \multicolumn{1}{|c|}{ HÁBITOS } & MÉDIA & MEDIANA & $\begin{array}{c}\text { DESVIO } \\
\text { PADRÃO }\end{array}$ \\
\hline Gosto de muita variedade para minha escolha & 3,58 & 4 & 1,13 \\
\hline $\begin{array}{l}\text { Comprar para mim é um momento de lazer, onde gosto de } \\
\text { ficar conversando e passar um bom tempo na loja }\end{array}$ & 2,57 & 2 & 1,35 \\
\hline Comprar é cansativo, escolho o que preciso e vou embora & 2,77 & 3 & 1,38 \\
\hline $\begin{array}{l}\text { Conheço pouco sobre Moda e faço questáo de ser } \\
\text { acompanhado por um profissional que entenda para me } \\
\text { atender }\end{array}$ & 2,18 & 2 & 1,21 \\
\hline $\begin{array}{l}\text { Escolho o que quero, independente se está sendo usado nas } \\
\text { passarelas da moda ou náo }\end{array}$ & 3,83 & 4 & 1,24 \\
\hline Uso roupas para demonstrar minha personalidade & 3,33 & 3 & 1,26 \\
\hline Roupas são meros acessórios para mim & 2,29 & 2 & 1,16 \\
\hline Compro roupas, não me interesso por marcas & 3,23 & 3 & 1,36 \\
\hline Sou atraído(a) por promoçóes & 3,61 & 4 & 1,30 \\
\hline Prefiro pagar à vista, independente do valor & 2,85 & 3 & 1,32 \\
\hline $\begin{array}{l}\text { Sempre acompanho blogueiras e sites de moda para me } \\
\text { atualizar }\end{array}$ & 2,41 & 2 & 1,46 \\
\hline Pago o preço justo, nem o barato nem o caro & 3,75 & 4 & 1,11 \\
\hline
\end{tabular}

Fonte: Dados da pesquisa (2017).

Os itens de menor concordância foram: "Não pergunto preço quando quero comprar um item de moda, escolho aquilo que gosto e pago o que for preciso" (2,37), "Conheço pouco sobre Moda e faço questão de ser acompanhado por um profissional que entenda para me atender" $(2,18)$, "Roupas são meros acessórios para mim"(2,29); o que permite analisar que o público respondente é composto por pessoas conscientizadas financeiramente em relação aos gastos que irão realizar com produtos de moda, e que não mede os gastos somente no seu desejo de adquirir o produto. Demonstra também que é um público que se considera suficiente para escolher aquilo que gosta e procura, sem a dependência de auxílio profissional. Sáo pessoas que valorizam a moda ao ponto de discordar que roupas são meros acessórios, dando a entender que roupas são sim importantes para a sua personalidade e uso. É um público de hábitos de consumo conscientes, mas que valorizam aquilo que consomem.

Já os itens que mais se aproximaram da concordância nos resultados obtidos, ainda que na escala média da neutralidade, foram os: "Gosto de muita variedade para minha escolha" $(3,58)$, "Escolho o que quero, independente se está sendo usado nas passarelas da moda ou não" $(3,83)$, "Pago o preço justo, nem o barato nem o caro" $(3,75)$; esses hábitos e características demonstram um público que se aproxima ao se considerar apreciador de variedades. Demonstra também ser próximo da não importância aos conceitos efetivos da moda, ao que é utilizado e ditado nas grandes passarelas mundiais, ao mesmo tempo em que valoriza seu gosto e suas próprias preferências estão também ligado ao que está sendo tendência. E por fim reafirma a responsabilidade e consciência financeira acima descrita, 
onde pagar o preço justo é importante, mas a atratividade por preços baixos também é prezada, conforme foi visto nas respostas ao que valoriza na escolha da loja preferida.

Por fim foram abordadas as sugestóes de melhoria que os respondentes mencionaram ao discutirem a atuação do mercado de moda de Cuiabá. A maior parte das sugestóes permanece na diminuição dos preços altos que se deparam ao adquirirem tais produtos, não conseguindo visualizar a compensação de qualidade, maior variedade na venda, que não fiquem somente nas principais tendências, mas que se expandam à estilos diferentes e que agradem a todos os gostos e voltam a mencionar a necessidade de melhora no atendimento pelas equipes de vendas do setor.

Conforme demonstrado nos Modelos de Negócios Canvas das empresas entrevistadas, a excelência em atendimento e um preço justo por seus produtos e serviços são mencionados redundantemente por todos, ficando evidente que ainda deve ser aprimorado no mercado regional, sendo assim, a discussão em torno dos fatores qualidade, atendimento e preço devem ser perseguidos pelas empresas do ramo, conforme afirmaram as entrevistadas. Esses itens serão aqueles tidos como ganhadores de pedido, fortes decisivos aos clientes que buscam a loja ideal para fornecer moda. Os dados coletados não têm intenção de definir qual loja é superior, mas sim demonstrar com uma amostra de consumidores da moda quais são suas maiores aflições, preferências, hábitos e gostos, garantindo o levantamento de informaçôes importantes e sugestóes de possíveis adequabilidades para aquelas entrevistadas e todo o universo de empresas que deseja oferecer itens de moda na cidade de Cuiabá e região se mantenham mais próximas e em compatibilidade com seu consumidor.

\section{CONSIDERAÇÓES FINAIS}

O presente estudo demonstrou a partir da pesquisa bibliográfica a importância do funcionamento do mercado da moda e a utilização da modelagem de negócios na construção da estratégia da organização, para que a mesma se posicione no mercado de maneira mais segura. Com o desenvolvimento da pesquisa, foi possível analisar a construção de modelos de negócios de empresas da cidade de Cuiabá e como os mesmos deixaram em evidência funções e objetivos essenciais de cada uma e de maneira rápida e prática, pela utilização da ferramenta Canvas, visualizar nas respostas obtidas na pesquisa com o mercado consumidor, os pontos que estavam em maior e menos sintonia com o mesmo.

Visando conhecer o nível de compatibilidade da oferta das empresas com as necessidades e desejos do mercado consumidor correspondente à suas segmentaçóes, a pesquisa demonstrou que os principais tópicos descritos pelas empresas são os mesmos de demanda dos consumidores, sendo três os de maior destaque: preço, qualidade e atendimento. Os respondentes ainda exigem melhorias no desenvolvimento desses serviços, mas responderam que esses são fatores decisivos para seus hábitos de consumo e importantes pontos na escolha da loja de moda preferida. Demonstrando assim que, mesmo que as empresas valorizem os mesmos pontos, com boa aderência, são chamadas a manterem contínua melhoria para a conquista do mercado.

Conforme a pesquisa é possível observar que, de modo geral, os consumidores buscam produtos de moda que os façam se sentir bem com aquilo que gostam de usar, 
o que garante a satisfação de seu gosto pessoal e sua personalidade. Conhecer a moda é importante, porém adaptá-la ao à sua personalidade se mostra uma característica mais forte do que a de seguir tendências firmemente. Demonstrou-se também que os itens básicos de um bom funcionamento para lojas do varejo são importantes e devem ser respeitados, como o respeito ao consumidor com um atendimento de qualidade e cordial, segurança de que o preço oferecido é justo e que, principalmente, se mantém condizente à qualidade que o produto oferece.

Já os hábitos de consumo também pesquisados auxiliam na compreensão das características do público enquanto consumidores. Quando observados os resultados de hábitos, observa-se um público independente, que não se prende à conceitos de moda para definirem seu estilo, mas sim para que esses auxiliem na escolha de peças que condizem com sua personalidade, como é possível observar nas respostas obtidas na Quadro 11. É um público que também demonstra a valorização de preços justos e peças de qualidade, que estejam em concordância com a precificação, conforme a mesma tabela.

Podem se definir como questóes limitadores do artigo a exploração de um maior número de entrevistados. Sugere-se para futuros estudos a diversificação dos respondentes bem como a definição de amostragem probabilística. Além disso, os casos pesquisados servem para referência o segmento, mas não permitem a generalização de todo o universo de empresas de moda da região.

O presente artigo trouxe a informaçôes fundamentais dos consumidores da moda na regiáo de Cuiabá, que ressaltaram problemas reais e que devem ser considerados não somente pelas empresas entrevistadas, mas por todo o setor comercial de varejo. $\mathrm{O}$ estudo teve por objetivo auxiliar na percepção da importância do mercado da moda e como ele é fator de comunicação social e grande movimentador econômico. É um setor que sofre preconceitos quanto à sua segmentação, muitas vezes percebida como um mercado de luxo e que alcança poucas classes, mas é preciso perceber que a moda como desenho de comportamento e parte da vida das pessoas e como um meio de expressão.

\section{REFERÊNCIAS}

BANGS, Jr., David H. Guia Prático Planejamento de Negócios - Criando um plano para seu negócio ser bem sucedido. São Paulo: Nobel, 2002.

COBRA, Marcos. Marketing e Moda. São Paulo: Editora Senac São Paulo, 2007.

COOPER, Donald; SCHINDLER, Pamela. Métodos de Pesquisa em administração. 7. Ed. Porto Alegre: Bookman, 2003.

CRESWELL, John. Projeto de Pesquisa: Métodos qualitativo, quantitativo e misto 2. Ed. - Porto Alegre: Artmed, 2007.

DENZIN, Norman K. ; LINCOLN, Yvonna S. Handbook of qualitative research. - 2. Ed. Thousand Oaks, Califórnia: Sage Publications, 2000. 
DESS, Gregory; LUMPKIN, G. T.; EISNER, Alan. Strategic management. 3. Ed. New York: Sage Publications: 1994.

DORNELAS, Jose Carlos Assis. Empreendedorismo: Transformando Idéias em Negócios. Campus, 2005.

FERNANDES, Bruno; BERTON, Luiz. Administração Estratégica: Da competência empreendedora à avaliaçáo de desempenho. - 2. Ed. - São Paulo: Saraiva, 2012.

HITT, Michael; IRELAND, R. Duane; HOSKISSON, Robert. Administração Estratégica. 2. Ed. São Paulo: Cengage Learning, 2008.

KAPLAN, Robert; NORTON, David. A execução premium: a ontençáo de vantagem competitiva através do vínculo da estratégia com as operaçóes do negócio. Rio de Janeiro: Elsevier, 2008.

RIGBY, D.; BILODEAU, B. Management Tools and trends 2015. Bain \& Company, 2015. Disponível em: < http://www.bain.com/Images/BAIN_BRIEF_Management_ Tools_2015.pdf>. Acesso em 06 maio. 2018.

SEBRAE. Como elaborar um plano de negócios. Brasília: 2013.

MILES, Matthew B.; HUBERMAN, A. Michael. Qualitative data analysis. Thousand Oaks: McGraw-Hill, 2007.

NEIS, D. F.; PEREIRA, M. F; MACCARI, E. A. Processo de Planejamento Estratégico e Estrutura Organizacional: Impactos, Confluências e Similaridades. Brazilian Business Review, v. 14, n. 5, p. 479-492, 2017.

OLIVEIRA, Silvio Luiz de. Tratado de metodologia científica. São Paulo: Pioneira, 1997;

OSTERWALDER, Alexander; PIGNEUR, Yves. Business Model Generation: inovaçáo em modelos de negócios. Rio de Janeiro: Alta Books, 2011.

TEECE, D. J. Business Models, Business Strategy and Innovation. Long Range Planning, v. 43, n. 2-3, p. 172- 194, Apr-Jun 2010.

ZOTT, C.; AMIT, R. Business Model Design: An Activity System Perspective. Long Range Planning, v. 43, n. 2-3, p. 216-226, Apr-Jun 2010. 